\title{
Das Kapital: \\ siglo y medio de una síntesis revolucionaria
}

\section{OSCAR MAÑÁN*}

La crítica de la economía política clásica plasmada en El capital de Marx refundó la economía y creó una nueva filosofía opuesta al idealismo alemán, lo cual significa la gestación de una ciencia social crítica identificada con los explotados dentro del sistema capitalista. El capitalismo ha logrado generar una descomunal riqueza sin precedentes en otra forma de organización del trabajo; sin embargo, dicha riqueza se alimenta de la carne humana. Las relaciones sociales de producción capitalista están alcanzando los límites sociales y físicos del mundo contemporáneo y en conjunto amenazan la persistencia de la civilización humana. La necesidad de transformar el orden vigente es más apremiante aún que en tiempos de Marx. El capital constituye un andamiaje conceptual complejo y crítico para entender a profundidad la sociedad capitalista, las formas de producción y reproducción. Además, elabora una teoría de la historia capaz de hacer una historia de la teoría.

Cómo voy a creer, dijo el fulano que el mundo se quedó sin utopías. Mario Benedetti, Utopías

El libro primero de Das Kapital vio la luz el 14 de septiembre de 1867, hace 150 años. Considerada por el mismo Karl Marx como su obra cumbre, la publicación fue un parteaguas para las ciencias sociales modernas, y desde entonces ha sido uno de los libros más leídos de la historia. Entre sus múltiples obras, sin duda ésta es la más cuidada y sometida a la crítica de los principales amigos y también de

* Profesor de la Universidad de la República, Uruguay los detractores del momento. Graduada en la lucha teórica más feroz del siglo XIX, siglo fermental para las ideas que buscaban entender los cambios que esa revolución productiva que se abría paso generaba en las organizaciones sociales y políticas de la época. Pero, en específico, puesta a prueba en la discusión con los obreros, quienes más que nadie conocían (hasta entonces intuitivamente) y sufrían el proceso de producción de capital, a costa de sus vidas.

Estas reflexiones tienen un carácter conmemorativo e intentan aportar algunos elementos, tal vez no originales, pero interesantes a la hora de valorar el trabajo de Marx. Se espera alentar el estudio de este autor y no sólo el interés literario, ya que El capital, como pocos textos, describe y explica la esencia de las relaciones sociales contemporáneas. El 
esfuerzo teórico del autor se plasma de manera genial para captar una radiografía del capitalismo central del siglo XIX que hoy resulta una herramienta insoslayable en un afán por comprender las formas modernas del desarrollo capitalista y la dominación que conlleva. Asimismo, sigue siendo imperioso transformar el orden vigente, ahora las urgencias apremian aún más que en tiempos de Marx, la persistencia de la civilización humana está amenazada por la dialéctica perversa de las actuales relaciones sociales de producción en sus límites sociales y físicos.

Primero se enuncian algunos ejemplos dignos de emular, en especial, su ética y sus pri- mordiales contribuciones. Luego, se analiza la potencialidad de su obra para el estudio de la sociedad capitalista. También se discute la necesidad de confrontar las teorías a fin de evaluar su relativa fortaleza o debilidad, dejando de lado las elecciones apriorísticas sobre las verdades dominantes. A su vez, se cuestiona si realmente Marx ha sido refutado por tantos intentos expuestos en este trabajo. Se intenta abordar la influencia de Marx dentro del pensamiento latinoamericano y lo que todavía tiene que decir para la región. Por último, se efectúa una reflexión sobre cuál sería el derrotero de los estudios marxistas que pretenden seguir las enseñanzas del autor.
El capital constituye

una ingeniería

conceptual muy

completa y particular

para entender

la sociedad capitalista, la forma en que se

organiza

la producción

y cómo el hombre

se produce a sí mismo.

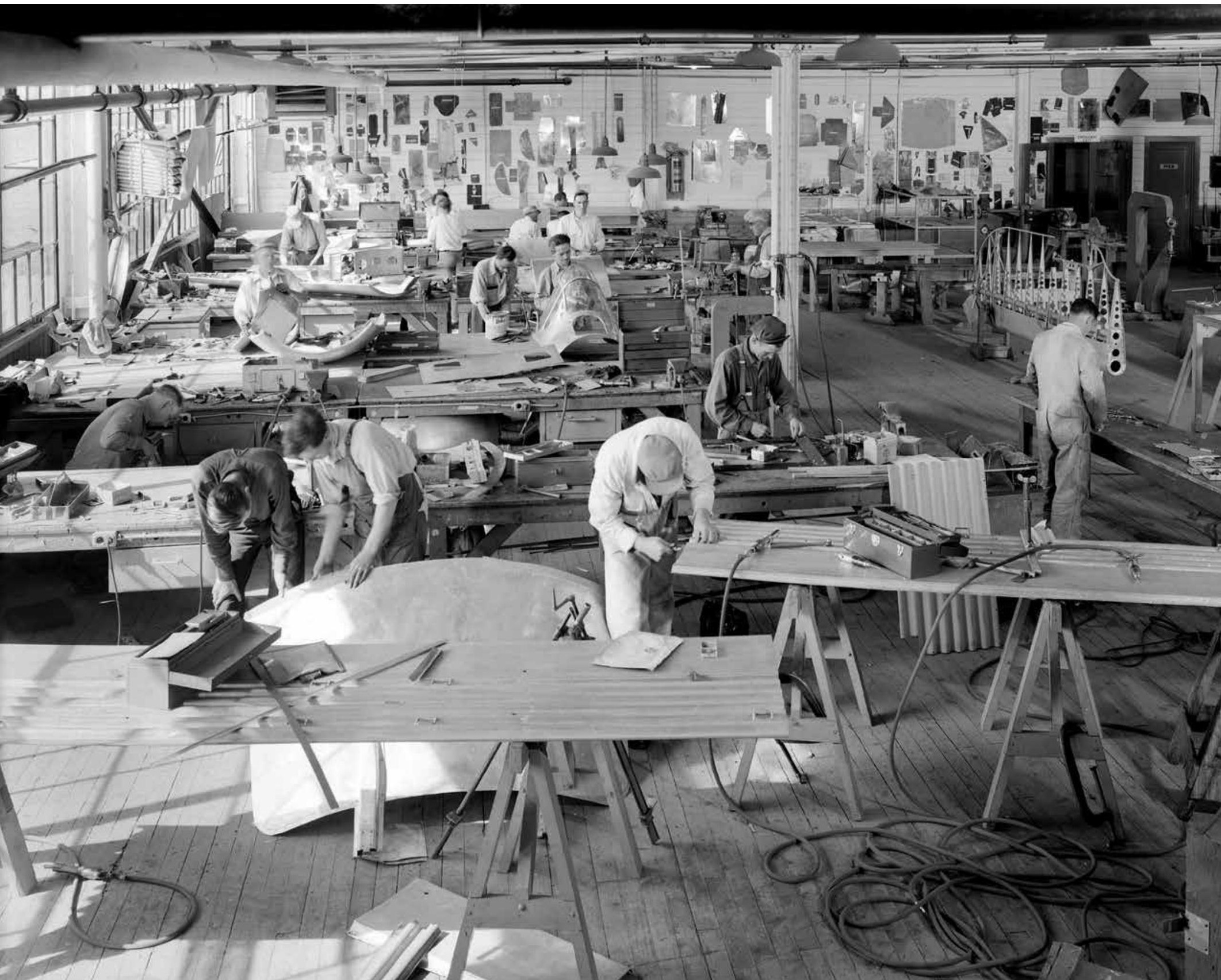




\section{El autor de El capital, contribuciones y legados}

La desvalorización del mundo humano

crece en razón directa de la valorización del mundo de las cosas.

Karl Marx

Marx fue uno de esos raros especímenes de la historia universal que se sacrificó a sí mismo, como a su familia, en un sentido solidario con el sufrimiento ajeno. Vivió en la extrema miseria, alentado por dar cuenta de las contradicciones sociales de su tiempo y por crear un método científico de análisis social que permitiera entender el desarrollo de las fuerzas productivas sociales. También se identificó con los desposeídos, con los que sólo contaban con sus brazos y que eran los responsables de generar la riqueza de un país, para que los menos, basados en un régimen de propiedad despótico, dispusieran de los frutos. Prueba de su pensamiento solidario es la carta a Engels del 30 de abril de 1867, ${ }^{1}$ donde rescata las penurias de su vida familiar en la pobreza abrumadora:

Todo el tiempo que podía consagrar al trabajo debí reservarlo a mi obra, a la cual he sacrificado mi salud, mi alegría de vivir y mi familia (...) Si fuéramos animales, podríamos naturalmente dar la espalda a los sufrimientos de la humanidad para ocuparnos de nuestro propio pellejo. Pero me hubiera considerado poco práctico de haber muerto sin al menos haber terminado el manuscrito de mi libro.

Su crítica de la economía política clásica no sólo refundó la economía, sino que creó una nueva filosofía que opuso al idealismo alemán y propició el nacimiento de una ciencia social crítica, que desde sus propias bases se identifica con los perdedores de este sistema económico. Éstos explican a la vez la descomunal riqueza

${ }^{1}$ Karl Marx, Friedrich Engels: werke (MEW), Band 30, Alemania, Dietz Berlin, [1860] (1990), p. 542. producida como ninguna otra forma de organización del trabajo anterior. En contraposición, esa riqueza se alimenta de la carne humana, lo que lleva a Marx a plantearse la necesidad imperiosa de su superación. Engels expuso de forma magistral:

Así como Darwin descubrió la ley del desarrollo de la naturaleza orgánica, Marx descubrió la ley del desarrollo de la historia humana: el hecho, tan sencillo, pero oculto bajo la maleza ideológica, de que el hombre necesita, en primer lugar, comer, beber, tener un techo y vestirse antes de poder hacer política, ciencia, arte, religión, etcétera; que, por tanto, la producción de los medios de vida inmediatos, materiales, y por consiguiente, la correspondiente fase económica de desarrollo de un pueblo o una época es la base a partir de la cual se han desarrollado las instituciones políticas, las concepciones jurídicas, las ideas artísticas e incluso las ideas religiosas de los hombres y con arreglo a la cual deben, por tanto, explicarse, y no al revés, como hasta entonces se había venido haciendo. Pero no es esto sólo. Marx descubrió también la ley específica que mueve el actual modo de producción capitalista y la sociedad burguesa creada por él. El descubrimiento de la plusvalía iluminó de pronto estos problemas, mientras que todas las investigaciones anteriores, tanto las de los economistas burgueses como las de los críticos socialistas, habían vagado en las tinieblas. ${ }^{2}$

El capital es un libro fervorosamente referenciado, muchas veces citado, pero no siempre igualmente estudiado. En la mayoría de las universidades de América Latina fue por mucho tiempo una referencia obligada de estudio y profundización en las clases de filosofía, economía, antropología, sociología, entre otras disciplinas. $\mathrm{Al}$ sur de América, las dictaduras militares lo volvieron un libro indecente, en las democracias emergentes tímidamente se recuperaron

${ }^{2}$ Friedrich Engels, Discurso ante la tumba de Marx, 1883, en https://www.marxists.org/espanol/m-e/1880s/83-tumba. htm 
espacios de reflexión y estudio. Luego de la caída del llamado «socialismo real», como la derrota ideológica que sufrieron los grupos revolucionarios y la clase obrera más movilizada con el triunfo del proyecto «neoliberal», desplazaron estos estudios por las teorías neoclásicas.

La cruda y terca realidad se impuso para rescatar los conceptos fundamentales de este libro. Las crisis de «nueva generación» Comenzada en México (1994-1995), seguida por Brasil (1998) y el sudeste asiático (1997-1998) y Río de la Plata (2001-2002) (nombradas en la región como «efectos Tequila, Samba, Tango

y Candombe») trajeron consigo un sistema financiero desregulado políticamente y aperturas irrestrictas de las economías emergentes, promovieron de nueva cuenta las lecturas de Marx para entender las crisis capitalistas.

No es un libro difícil (decía su autor), salvo el capítulo referente a las formas de valor. ${ }^{3}$ No obstante, constituye una ingeniería conceptual muy completa y particular para entender la sociedad capitalista, la forma en que se organiza la producción y cómo el hombre se produce a sí mismo a partir de la producción de sus medios de vida. Busca realizar una teoría de la historia capaz de hacer una historia de la teoría.

De esa manera se pensó El capital, primero se desarrollaron los conceptos que pudieran aprehender la sustancia de las relaciones sociales de producción, las categorías y dimensiones analíticas que median para dotar de contenido a tales conceptos, lo que significaba una crítica sobre su influencia en las re-

\footnotetext{
${ }^{3}$ Karl Marx, El capital (prólogo a la primera
} edición alemana), Moscú, Progreso, 1980. laciones sociales. Se cuidó de forma obsesiva el método de exposición (que no coincide sensu stricto con el método de investigación y la historia del proceso social en que se presentan los hechos). Después se aboca a las condiciones de circulación y distribución, al análisis del capitalismo en movimiento. La pretensión era terminar con una historia de las teorías de la plusvalía (esfuerzo que hicieron sus sucesores con los apuntes de sus estudios para tener un panorama del trabajo inconcluso).

La concepción de ciencia con que trabaja Marx no embona siempre con la correspondiente al sentido popperiano dominante.
Marx fue producto de las circunstancias, en un mundo que le permitió ser un gran revolucionario.

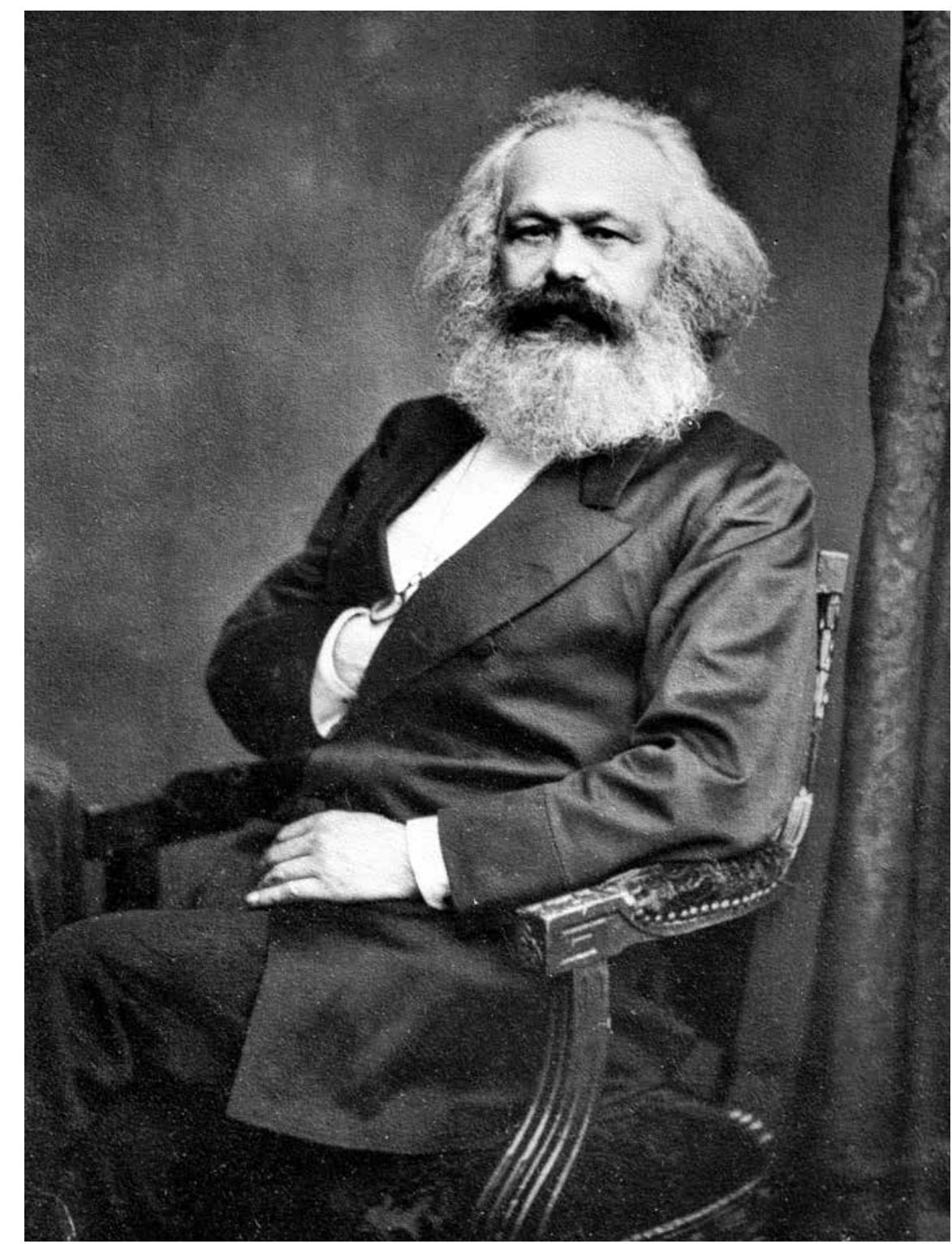


Cuando se refiere en concreto a la ciencia aplicada, aquella que es subsumida a los intereses del capital, que permite mejorar las condiciones de los medios de producción y por ende la productividad del trabajo y del sistema económico en general, Marx utiliza el sentido de la ciencia «normal». Sin embargo, como lo prueba Dussel ${ }^{4}$ en su estudio sobre los Manuscritos del 61-63, la que practica Marx es una ciencia «crítica», cuyo sentido es «crítica de la apariencia». Conocida es la frase donde sostiene que «toda ciencia sería superflua si la forma fenoménica (Erscheinungsform) y la esencia de la cosa coincidieran inmediatamente». ${ }^{5}$

Entonces, la ciencia no es necesariamente la actividad que hacen «los científicos», sino que bajo tal comprensión es una actividad teórico-práctica que tiene la intención de explicar la esencia de los fenómenos. En tanto que muchos conocimientos que «la ciencia normal» podría atribuirle a la ciencia no serían científicos, otras formas de conocimiento que aportan hombres vulgares que no son de ciencia sí podrían considerarse científicas. En el caso de que tales conocimientos contribuyan a la descripción conceptual, categorial, de un fenómeno y lo vuelven inteligible, entonces sería ciencia. En ocasiones, Marx tilda de «seudociencia» a algunos conceptos de los hoy considerados clásicos de la ciencia económica (como Smith y Ricardo) cuando carecen de categorías y mediaciones necesarias para vincular la apariencia fenoménica de la realidad con la esencia que explica el movimiento real. Lenin lo advierte en el mismo sentido:

De uno u otro modo, toda la ciencia oficial y liberal defiende la esclavitud asalariada, mientras que el marxismo ha declarado una guerra implacable a esa esclavitud. Esperar que la ciencia sea imparcial

${ }^{4}$ Enrique Dussel, Hacia un Marx desconocido. Un comentario de los Manuscritos 61-63, México, Siglo Xxi/Universidad Autónoma Metropolitana, 1988.

${ }^{5}$ Ibid, p. 289. en una sociedad de esclavitud asalariada, sería la misma absurda ingenuidad que esperar imparcialidad por parte de los fabricantes en lo que se refiere al problema de si deben aumentarse los salarios de los obreros disminuyendo los beneficios del capital. ${ }^{6}$

Marx, como él mismo manifestara, fue producto de las circunstancias, en un mundo que le permitió ser un gran revolucionario. Logró una síntesis muy influyente de todas los hitos históricos del siglo XIX, la lógica implacable de la especulación filosófica alemana, las luchas burguesas por la construcción política institucional que perpetuara su dominio en Francia y la «magia» de los avances científico-técnicos de la industria inglesa que le daría al capitalismo su misión histórica: revolucionar las fuerzas productivas materiales.

El legado de esta obra es de gran trascendencia, ya sea porque plantea conceptos y categorías analíticas útiles para entender la médula del sistema capitalista, o porque implica un método de trabajo minucioso que no soslaya ninguna perspectiva. Marx valoró, analizó, tomó o desechó cualquier idea proveniente de la entonces considerada ciencia del establishment o aquellas que venían de fuentes menos sacralizadas. Todas las alternativas eran válidas si contenían una explicación racional, congruente para el desarrollo de categorías analíticas que permitieran «quitar el velo» al movimiento de lo real. En adición, se opuso a la «seudociencia» que se quedaba en la descripción pura y llana de «la apariencia» de los fenómenos económicos y sociales.

Es apabullante la responsabilidad que conlleva el compromiso de su labor con los sectores explotados por la forma social dominante en que se organiza el trabajo. El que los profesionales que se desempeñan como formadores

\footnotetext{
${ }^{6}$ Vladimir Ilich Lenin, Marx, Engels, marxismo, Pekín, Ediciones Lenguas Extrajeras, [1913] 1998, p. 73.
} 
en las universidades (en particular las públicas de la región) tomen su ejemplo es el mayor tributo que podría hacérsele y que redundaría en futuras generaciones.

\section{Potencialidad de su obra}

Necesitamos otra educación para otra sociedad y otra sociedad para otra educación.

Karl Marx

Sin duda, su obra constituye una unidad integrada, seguramente unidad inacabada, por lo que no es posible presentarla como un cúmulo de verdades. En efecto, resulta una teoría viva y como cualquier expresión de la vida social no está exenta de contradicciones y posibles soluciones (síntesis transitorias, históricas); siempre múltiples en la medida en que devienen de hipótesis más o menos dominantes en cada época (Engels en la Dialéctica de la naturaleza muestra cómo un mismo fenómeno es pensado y conceptualizado de modo diferente si se observa bajo presupuestos diversos).

Marx representa a la vez continuidad y ruptura con los clásicos. Continuidad en la identificación del trabajo como fuente de valor y ruptura en lo que hace al enfoque teórico-epistemo-metodológico en el que el valor se conceptualiza y cualifica como una forma histórica de organización del trabajo. A diferencia de los clásicos, cuya preocupación era la determinación cuantitativa de los valores (como forma dada y preexistente), en Marx ésta aparece determinada por la organización social y su interés es explicarla. De ahí que en vez de tomar el camino de los clásicos, quienes hurgan en la utilidad de las mercancías, Marx reconoce la utilidad intrínseca de la mercancías (valor de uso) y se aboca al valor de cambio, que no sólo expresa utilidades subjetivas recíprocas de los agentes sino una determinación objetiva de la misma organización social.
Tal determinación objetiva acompaña a la organización del trabajo; en consecuencia, el valor es una expresión del trabajo y cuantitativamente se determina por su productividad social media. El trabajo socialmente necesario, en la expresión de Marx, es el trabajo vivo, el capital variable en su condición de agregar valor, por la «peregrina cualidad de la mercancía fuerza de trabajo de crear más valor del que ella gasta en el proceso de su producción». El trabajo ya objetivado (trabajo muerto) no agrega valor nuevo sino que transfiere valor cuando se amortiza con el uso.

Ésta es una diferencia de la conceptualización del valor en Marx y los clásicos: para él, valor y plusvalor son producto del trabajo socialmente necesario cuyo elemento dinámico de la contradicción es el trabajo vivo (capital variable), mientras que los clásicos ven al valor determinado por el capital total. En Marx, la creación de valor y plusvalor supone la lucha de clases; en los clásicos y seguidores, no necesariamente, ya que implica una «externalidad positiva» del proceso productivo. Las corrientes derivadas de los clásicos reducen las expresiones de valor a la idea de trabajo, por lo cual expresan el capital total reducido a cantidades físicas de capital y salario, lo que hace superflua la distinción de clase.

En este punto aparecen conflictos, por ejemplo: ¿qué es el capital? Como unidad cualitativa es un cúmulo de mercancías, definido como «dinero que genera más dinero»; en este caso al utilizar la expresión dineraria (dinero como otra mercancía con varias características: unidad de cuenta, permite el intercambio, expresa valor y hace posible reservar y acumular valor, etcétera). Existe otro debate acerca del punto de partida: «si el huevo o la gallina». En Marx el proceso de producción de plusvalía se encuentra en el centro del andamiaje social capitalista; no obstante, la circulación de dinero es el presupuesto lógico del capital (la fórmula es D-M-D'). Ello provoca numerosos problemas 
respecto a las características que en cada etapa adquiere el dinero. El proceso de producción se enfoca en la creación de valor, por lo tanto el eje más preciado para la formación y acumulación de capital; pero este capital que comienza el ciclo con afán de incrementarse supone un proceso de circulación anterior. Efectivamente, necesita dinero inicial con pretensiones de convertirse en capital, que en dicho momento inicial no es de suyo capital, sólo lo será cuando «se enloda las manos» en el proceso productivo.

Un punto de partida clave, emprendido por Marx, es el trabajo humano, en su doble carácter: como productor de medios de vida y como productor de vida misma. Este último aspecto de la esencia del trabajo casi no se referencia en las ciencias sociales modernas y quizá es el gran elemento a resaltar para apuntar una organización social diferente. En particular, Marx hizo hincapié en el «trabajo vivo», como sustento para mostrar su crítica de la economía política del capitalismo; si bien se había vinculado el trabajo con la riqueza, no se lograba todavía el nexo con la organización social en conjunto.

Tal crítica, en su sentido profundo, implica la negación de lo existente (como negatividad, sostendría Adorno) y a la vez como inicio para la superación indispensable de la forma de organización social llamada capitalismo. Esto exige, como lo hizo Marx, ponerse en la piel de los «jodidos» del sistema capitalista («las víctimas», como propone Dussel), fundamentalmente trabajadores, aspirantes a trabajadores, campesinos empobrecidos y acosados por la colonización del mundo de las mercancías; marginados en todos los sentidos del sistema económico pero que forman parte del ejército industrial de reserva, o simplemente, de la imagen de un futuro poco alentador.

\section{Necesidad de confrontación de las teorías}

Debemos ser pesimistas en la razón
y optimistas en la práctica.

Antonio Gramsci

No sólo es deseable sino que se convierte en necesario el discernir cuáles herramientas teóricas actuales se ajustan más a la dinámica social y, por ende, cuáles serán más beneficiosas para la práctica cotidiana. La teoría económica neoclásica es la teoría del capitalismo, la que normalmente políticos, académicos y profesionales del establishment reivindican como el «saber sabio» que se ha vuelto dominante en las universidades de la región. Sin embargo, la teoría marxista y sus variantes no aparecen representadas en los programas de ciencias sociales con la importancia que deberían.

Cuando se comparan las teorías dominantes en la actualidad y sus bases teóricas, se aprecia que la vertiente walrasiana es la más referenciada en la perspectiva neoclásica. En este caso, la teoría de Marx sigue presentando aspectos por demás valiosos y particularmente más trascendentes. En William S. Jevons y también en León Walras hay un intento de ahistorizar las categorías de la ciencia económica. Jevons advierte que si bien le otorga importancia a la ciencia histórica, su interés está en compartimentar las disciplinas para lograr eficiencia, por lo que propone extraer «lo social» hacia una nueva rama científica. Dicha ciencia es denominada por Spencer sociología, entendida como ciencia de la evolución de las relaciones sociales. ${ }^{7}$ Jevons afirma que la búsqueda de una «mecánica general» debe hacerse con el método que John Stuart Mill llamó método deductivo físico concreto

${ }^{7}$ William S. Jevons, The theory of political economy (tercera edición), London, Macmillan, 1888, en http://oll. libertyfund.org/titles/625 
y, con ello, investigar la ley psicológica obvia de que el mayor beneficio es preferido al menor y, luego, analizar el impacto de esa ley en la sociedad. ${ }^{8}$

En ese sentido, Walras separa intercambio, producción y distribución. Sólo el intercambio es susceptible de estudiarse en los dominios de la ciencia pura, dejando la producción y la distribución a los ámbitos del arte y la ética, respectivamente. ${ }^{9}$ De este razonamiento se desprende su incapacidad para el análisis de las cuestiones dinámicas de la economía, escasez y apropiación, dos claves para entenderlas que no forman parte de una disciplina científica.

Es obvio que, la vertiente walrasiana soslaya muchos aspectos que hoy son problemas en la explicación económica de las relaciones sociales. El tratamiento que Blaug hace en Teoría económica en retrospectiva de la economía marxista es también una castración literal de lo que a su juicio pertenece a la filosofía, la sociología u otros ámbitos de las ciencias sociales. Además, el punto de partida es dar cuenta del comportamiento individual, la comprensión del todo vendrá por añadidura; léase, una simple agregación de las conductas individuales. En cambio, el eje central del pensamiento de Marx es explicar la totalidad de la dinámica social; en consecuencia, las explicaciones de los fenómenos individuales son determinadas por la articulación de grupos sociales que permiten la comprensión de la totalidad.

El empirismo y el individualismo metodológico no son ajenos a la ciencia económica contemporánea, ya estaban presentes en Jevons y Walras en su persecución de la eficiencia. Tal forma de «empirismo abstracto» es tan poco útil como la «gran teoría» que trata a sus hipótesis como inviolables y nunca se atreve a tes-

\footnotetext{
${ }^{8}$ Idem.

${ }^{9}$ Bolívar Echeverría, «Marxismo y teoría económica contemporánea. Confrontación de puntos de partida», Críticas de la Economía Política, núms. 18/19, 1981.
}

tar su certeza en el mundo real. ${ }^{10}$ Por su parte, Hegel alertaba:

Pensar el mundo empírico (...), esencialmente, transformar su forma empírica y cambiarla en algo universal (...) la materia percibida, cuando es determinada mediante la universalidad, no subsiste en su primera forma empírica (...) Decir que este salto no debe darse, es decir que no se debe pensar. ${ }^{11}$

Por ende, el nivel de abstracción de la teoría económica que se analiza determinará el tipo de validez que debe exigírsele. Según el criterio friedmaniano, el resultado científico de una teoría es independiente de cuán reales sean sus supuestos. Es decir, no importa que tan creíbles son los supuestos, si conducen a resultados o predicciones coherentes con la experiencia. En resonancia con este criterio la formalización de la ciencia económica, en el entendido de que si se extiende al infinitum los ceteris paribus, la verdad tendrá un carácter menos discutible. A lo anterior se podría contestar con una máxima de la misma estadística, a medida que se disminuye la posibilidad de error, se termina en juicios menos relevantes.

Entonces, es posible reducir las abstracciones de la realidad, o modelarla de la forma más simplificada, hasta caer en un juicio del tipo si A se da, y todas las demás condiciones se mantienen invariantes, es probable que ocurra B. El ejemplo muestra, a modo de caricatura, los cambios dominantes en la teoría económica y el supuesto «grado de eficiencia». Cabría preguntarse, ¿es posible tildar a un enunciado de este tipo como teoría económica? Según Steindl, ${ }^{12}$ Kalecki había prevenido que la matemática y la computación «estaban equipadas como para cubrir con un manto científico la falta de

\footnotetext{
${ }^{10}$ Charles Wright Mills, La imaginación sociológica, Buenos Aires, Amorrortu, 1982.

${ }^{11}$ Georg Wilhelm Friedrich Hegel, Enciclopedia de las ciencias filosóficas, México, Porrúa, 1977, p. 33.

${ }_{12}$ Josef Steindl, «Reflexiones sobre el estado actual de la economía», Investigación Económica, núm. 171, 1985.
} 
sustancia económica». Si los juicios anteriores obtienen el estatus de teoría económica, entonces se deberían usar elementos evaluativos del campo de la lógica formal, no podría pedirse que predigan el movimiento económico.

La teoría marxista, en contraste, deberá ser exigida desde su coherencia lógica y podrá ser evaluada en su capacidad de interpretar los fenómenos sociales más comunes. Entre ellos, su teoría de la tasa de ganancia podrá ser interrogada acerca de las condiciones que enmarcan la competencia capitalista, como limitantes y estrategias que los organizadores de la producción disponen para conseguir el fin de su actividad productiva: la ganancia. Aquí no se alude a un simple hecho de optimización matemática, sino de relaciones sociales entre grupos económicos obligados por niveles diferenciales de intereses o necesidades. En tanto, la teoría de los ciclos económicos indica en qué niveles de la tasa de retorno se producirán innovaciones tecnológicas, con lo que se apuntala una restauración de la misma. Si se aborda la teoría del crecimiento económico, el marxismo evidencia los impactos del datum tecnológico en las variables distributivas y de su necesariedad para el incremento de la tasa de retorno del capital.

La teoría de la distribución se explica en dicho esquema teórico como una variable subordinada a las necesidades de la acumulación de capital y se relaciona - a través de la teoría de la plusvalía - con la dinámica de la tasa de ganancia. El vínculo acumulación-distribución implica una asociación contradictoria entre los dueños de los medios de producción y los vendedores de la fuerza de trabajo; asimismo, permite determinar el nivel y la densidad de la absorción de fuerza de trabajo que requiere la reproducción económica. Como contrapartida se detectan los límites de la reproducción, ya sean provenientes de la oferta de capital o de mano de obra. Y, en específico, los efectos que tales relaciones sociales tienen en las tensiones y la estabilidad política, tópi- cos cercanos a la sociología, las ciencias políticas y otras ramas de las ciencias sociales.

En cambio, para la vertiente walrasiana, el tema distributivo no pertenece al análisis económico y su nivel se acepta como un dato a priori, determinado por «arte de magia» fuera del proceso productivo. La lógica analítica de la teoría neoclásica — la cual es básicamente estática - analizará por separado «momentos distintos» de desarrollos tecnológicos, pero no explicará el tránsito de unos a otros. Incluso, la teoría «moderna» del crecimiento endógeno, si bien ha endogeneizado las variables tecnológicas, aún no ha aportado una explicación coherente de cómo se relacionan específicamente con la dinámica del crecimiento —el avance técnico sigue siendo un residuo que se explica por una o muchas variables endógenas..$^{13}$

\section{¿Marx refutado?}

Igual que en la religión el hombre es dominado por el producto de su propia cabeza, en la producción capitalista lo es por el producto de su propia mano.

Karl Marx

Es muy común que al análisis marxista se le atribuya la idea de «cosmovisión» porque intenta dilucidar todos los ámbitos del devenir social. Se le acusa de no ser una teoría científica, debido a que toma partido por una de las clases sociales en pugna, el proletariado. No obstante, la teoría walrasiana del equilibrio no es una mera descripción exenta de valoraciones. Una economía se precia de estar en equilibrio, que se reconoce como el estado ideal, cuando no existen fuerzas internas que cambien dicho estado. Si a esa definición se le agrega la noción de óptimo paretiano, se tendrá una idea de bienestar sui generis que engloba, a su vez, una particular concepción de justicia.

${ }^{13}$ Robert M. Solow, «Perspectives on growth theory», Journal of Economic Perspectives, vol. 8, núm. 1, 1994. 
Cuando se llega a una transacción económica bajo los supuestos anteriores es porque hubo por lo menos un ganador y ningún perdedor en el acto de transacción. Si hubo por lo menos un ganador, entonces se lograría un estado de equilibrio de mayor bienestar, por lo que la teoría respalda a «los ganadores» del proceso, es decir, es «solidaria» con los triunfadores.

Tan cierto es lo anterior que para algún leal seguidor de esta teoría la concepción de desempleo no existe como producto de las relaciones económicas, sino debido a la decisión libre, «de elección racional» del trabajador. Robert Lucas, economista distinguido con la buenaventura de un premio Nobel, incluso en una oportunidad comentó que «el desempleo involuntario no es un hecho o un fenómeno que haya de ser explicado por los economis- tas», éste no es más que una «construcción teórica»; en tanto, el desempleo abierto en Estados Unidos en ese periodo fue de $6.4 \mathrm{mi}-$ llones de personas. ${ }^{14}$

Es notorio que la teoría neoclásica esgrime un grado de parcialidad asombroso, además su evaluación lógica — después de los trabajos de Sraffa y Garagnani - deja mucho que desear. Por ejemplo, desempleo, distribución, origen de las ganancias, estabilidad del equilibrio, cambios de estados, son todos enunciados que se descartan del análisis, se suponen dados o simplemente no se abordan con seriedad.

${ }^{14}$ Robert Lucas (1978), citado por José Carlos Valenzuela, Crítica del modelo neoliberal: el FMI y el cambio estructural, México, Facultad de Economía-Universidad Nacional Autónoma de México, 1991.

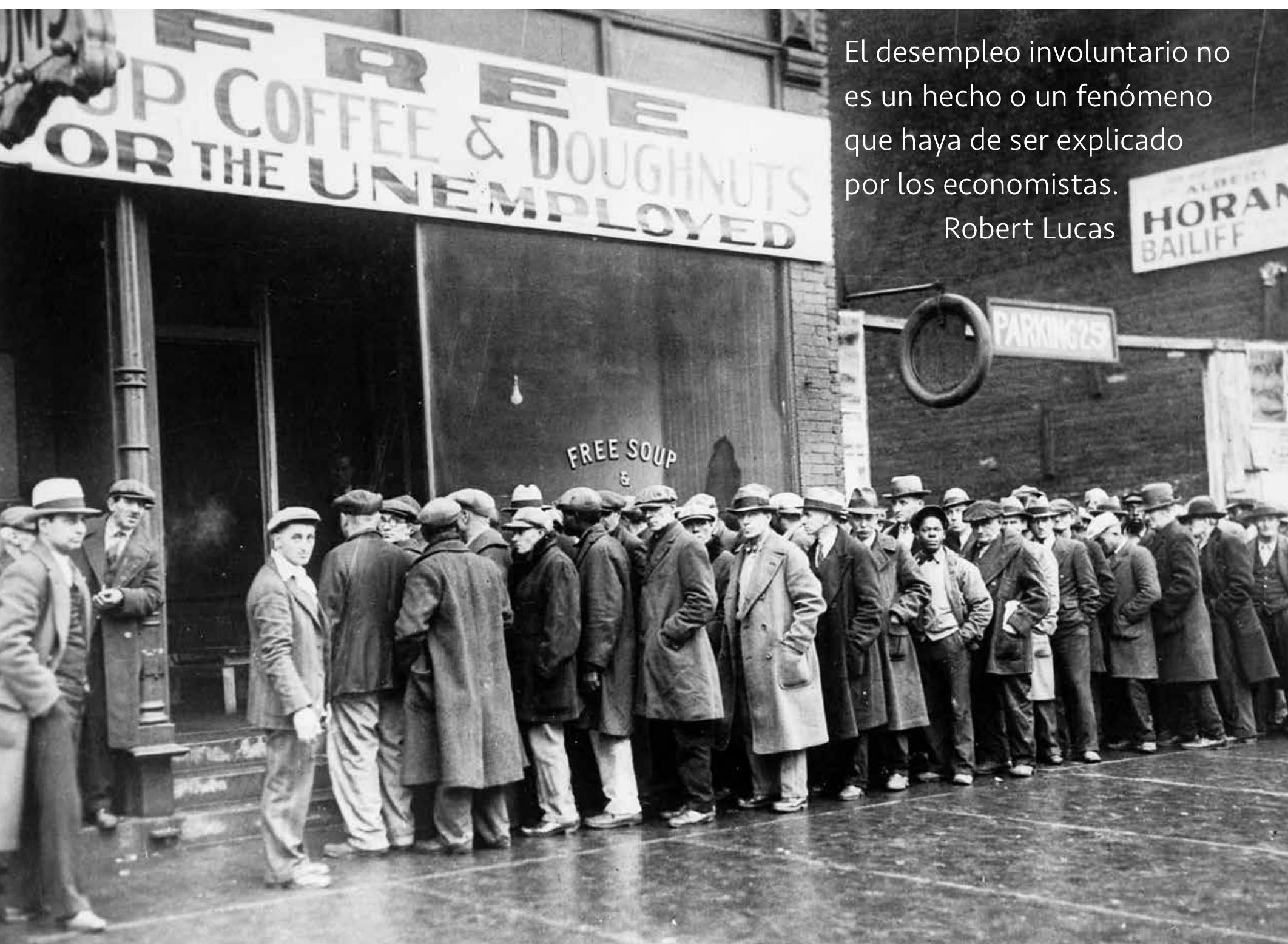


La teoría marxista no está exenta de dificultades. Son ya muchos los intentos por refutarla; pero, parafraseando a Galileo, eppur si muove. Más allá de los ataques de las teorías competidoras, la de Marx resiste los intentos de negación o refundación surgidos de sus propias entrañas..$^{15}$ De ahí que no se pueda afirmar, en el sentido kuhniano, que no genera nuevas ramas de interés y soluciones. En ese sentido, el marxismo puede tildarse de paradigma, cuestión que no se ajustaría a la teoría económica neoclásica como tal.

Es práctica común de este siglo que la teoría burguesa aparezca «metamorfoseada» en autores que han tenido algún pasaje por el marxismo. El resurgir del neoricardianismo con los aportes de Piero Sraffa parte de un cuestionamiento a la solución lógica del problema de la transformación de valores a precios — basado en Ladislao von Bortkiewicz - que lleva a los autores a plantear un sistema de precios de producción que haría obsoletos los fundamentos de la teoría del valor marxista. No es intención de este trabajo hacer una crítica a la crítica, empero esta postura se basa en un problema totalmente heterogéneo al formulado por Marx, las confusiones pueden rastrearse en un mal entendimiento de El capital —en especial las formas del valor - desde su comienzo. ${ }^{16}$

La teoría de la regulación es otra vertiente relevante en el análisis social que intentó resignificar el marxismo. Sus representantes clásicos son Alain Lipietz, Robert Boyer, Michel Aglietta y Gérard de Bernis, quienes sugieren la necesi-

${ }^{15}$ Fred Moseley, Money and totality. A macro-monetary interpretation of Marx's logic in capital and the end of the «Transformation problem», Leiden/Boston, Brill, 2016; Fred Moseley, «Marx's theory: true or false? A marxian response to blaug's appraisal», en Fred Moseley (ed.), Heterodox economic theories. True or false?, Aldershot, Edward Elgar, 1993; Oscar Mañán, «Teoría marxista y transformación de valores en precios, 117 años de controversias», Estudios Críticos del Desarrollo, vol. 2, núm. 3, 2012.

${ }^{16}$ Fred Moseley, «Explanatory progress or retrogression in economics? A Marxian response to Hausman», paper presented at Mt. Holyoke College, june, 1993. dad de sustituir las concepciones «fosilizadas», «dogmáticas» $\mathrm{y}$ «mecanicistas» al inscribirse en la tradición poskeynesiana o neoricardiana. Adoptan una postura ecléctica — «antiteórica» según Boyer - para no desperdiciar los aportes de la teoría subjetivista ni aquellos emanados de la escuela objetiva. Por eso introducen «categorías intermedias», «conceptos concretos» que superarían las «generalidades» marxistas. En realidad confunden lo «concreto» con lo superficial, y sus «categorías intermedias» no hacen más que reproducir las apariencias con que el sistema capitalista seduce a sus admiradores. Ejemplo de lo anterior son las elucubraciones de Gérard de Bernis ${ }^{17}$ cuando reflexiona en un modelo de desarrollo alternativo.

Luego, se sucedieron varios enfoques que buscan refuncionalizar al marxismo. La vertiente conocida como «marxismo analítico» se empeñó en «darle sentido a Marx», ${ }^{18}$ en un contexto más contemporáneo. Sin embargo, ¿cómo se pretende dar sentido a Marx? Por supuesto, en el sentido de la teoría dominante, hegemónica. En opinión de Moseley, incluso Roemer no reprime sino que enfatiza su propio deseo de reinterpretar la teoría de Marx en los términos de la «teoría del equilibrio general».

Dicha corriente retoma algunas de las críticas del neoricardianismo, en particular el individualismo metodológico al mejor estilo neoclásico, con el que tratará de dotar al análisis marxista de los microfundamentos «tan necesarios» que brindan coherencia a su enfoque metodológico. El caso típico es Roemer, quien parte de individuos atomísticos ontológicamente anteriores a la sociedad —algunos Robinson Crusoe ideales, recuérdese que el personaje literario tenía una historia, un

\footnotetext{
${ }^{17}$ Gérard de Bernis, «Un mundo de trabajo para todos», Economía Informal, septiembre, 1993, pp. 301-331.

${ }^{18}$ Jon Elster, Making sense of Marx, Nueva York, Cambridge University Press, 1985.
} 
pasado como cualquier hombre - y en un determinado momento irrumpen en el proceso de intercambio con dotaciones diferenciales: «El proceso histórico que origina las dotaciones iniciales donde comienza mi modelo no es un tema de mi análisis. Es un tema para el historiador». ${ }^{19}$ Como ejercicio intelectual podrían buscarse «las siete semejanzas» con Jevons. Si el modelo logra los objetivos, «el modelo ha hecho las abstracciones adecuadas: ha omitido cosas que no son básicas

${ }^{19}$ John E. Roemer, «Exploitation and labour theory of value», Economic and Political Weekly, vol. 21, núm. 3, 1986, p. 138. para su tema y ha concentrado nuestra atención correctamente». ${ }^{20}$ Cualquier semejanza con Friedman es pura casualidad.

No es difícil concordar en que los intentos de refutación del marxismo han sido una maraña de confusiones y que en realidad en la mayoría de los casos fueron anticipados por Marx en las discusiones con los apologistas del statu quo de su época. En síntesis, el avance en el planteamiento de los temas económicos en los desarrollos neoclásicos contemporáneos es muy sospechoso; si se es riguroso,

${ }^{20}$ Idem.
Esperar que la ciencia sea imparcial en una sociedad de esclavitud asalariada, sería la misma absurda ingenuidad que esperar imparcialidad por parte de los fabricantes en lo que se refiere al problema de si deben aumentarse los salarios de los obreros disminuyendo los beneficios del capital.

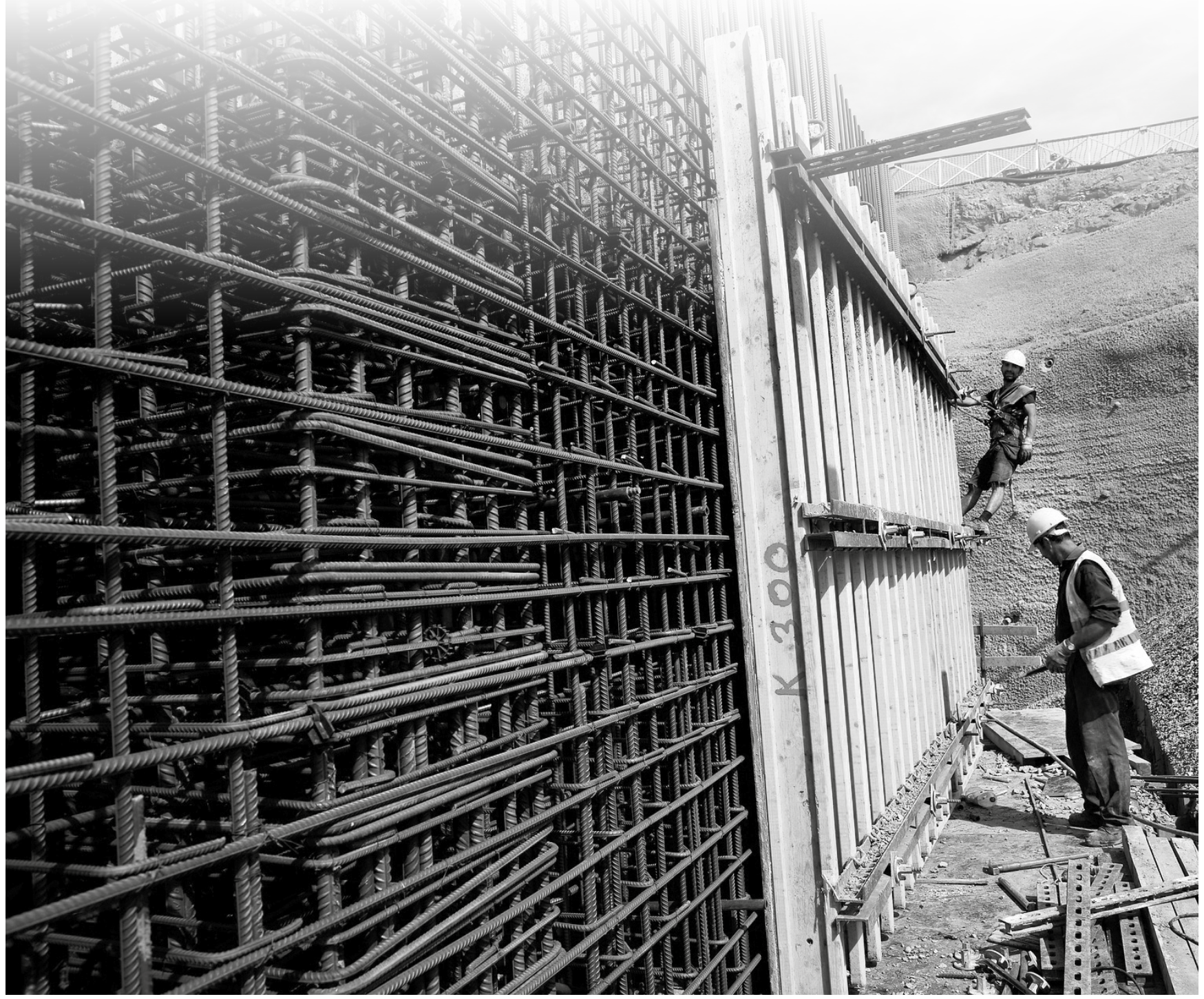


quizá se encuentren ciertas reminiscencias anteriores a los clásicos.

\section{Marx en América Latina tiene aún mucho que decir}

No consigo parar de creer que estos tiempos de resignación, desprestigio de la pasión humana y arrepentimiento del humano compromiso, son nuestro desafío pero no son nuestro destino. Eduardo Galeano, Mea Culpa

Marx influyó de modo importante en la región, si bien no directamente y, a menudo, no se lo reconoce. No obstante, el proceso económico del capital sigue avanzando y subsumiendo a la región a los designios del mercado mundial. Una parte inconclusa del plan de Marx fue el análisis del mercado mundial y las categorías que podían llevar a la subsunción de unas economías por otras. Numerosos estudiosos se concentran en el funcionamiento de la ley del valor a escala local y pocos en el estudio de la acumulación en el nivel global y lo que implica para los pueblos latinoamericanos.

Todavía queda bastante trabajo por realizar, desde el punto de vista teórico es preciso generar las categorías adecuadas para el análisis de la acumulación en el mercado mundial, en especial, las transferencias de valor. Asimismo, falta vincular las condiciones de acumulación a escala nacional y el nexo entre los capitales nacionales que se transnacionalizan con otros de mayor desarrollo relativo.

No cabe duda que el estudio en profundidad de El capital y el desarrollo de categorías que ayuden a comprender la especificidad de la acumulación de capital en la región entrañarían una revolución teórica indispensable en esa coyuntura. Esto no implica desestimar los avances en siete décadas de pensamiento latinoamericano o en casi dos siglos de pensamiento marxista, sino subrayar la necesidad de construir una síntesis con sentido teórico y estratégico para mejorar las condiciones de vida en América Latina.

Las teorías de la dependencia rescatan en cierta medida algunos conceptos y categorías presentados por El capital, en muchos casos de manera parcial o deficitaria, casi siempre sin respetar el marco teórico donde tales categorías cobran sentido. Marini es, tal vez, el exponente más original, al intentar teorizar ciertos aspectos de la competencia capitalista que enfrentan a los ciclos de capital industrial del centro con mayor composición orgánica que los de la periferia, mediante el análisis de sus consecuencias para la organización social dependiente. Sus resultados son debatibles en cuanto a la esencia y la apariencia de tales procesos sociales.

En particular, el marxismo latinoamericano fue más eficaz al describir e interpretar las relaciones capital-trabajo en cada uno de los países, aunque abundó menos en la relación entre capitales nacionales heterogéneos y escasamente sobre la «competencia transnacionalizada» entre los capitales nacionales dependientes transnacionalizados y los capitales de mayor composición de valor de los países centrales. Tampoco se abordaron las diferencias salariales como forma crucial en la explicación del intercambio desigual dentro del mercado mundial. Si bien no genera valor sí lo distribuye cuando extrae, expropia riqueza desde el mundo dependiente e incrementa las grandes brechas mediante la nivelación de precios que ocurre en la competencia. Brechas que no son sólo económicas, sino políticas, militares, sociales, culturales, tecnológicas, entre el mundo pobre, dependiente, colonizado y el mundo rico, colonizador y esclavizante.

Tanto de una lectura atenta de Marx como de sus divulgadores es posible identificar varios mecanismos en los que se ejerce la dependencia. De ellos se destacan las siguientes formas: 
a) Cuando hay competencia entre capitales transnacionales de diferente composición de valor y opera una transferencia de valor desde los capitales transnacionalizados de menos desarrollo (la esencia de esta dependencia marxista).

b) Cuando no existe competencia y las mercancías son producidas por capitales transnacionales de países periféricos, pero la demanda mundial se concentra en países cuyos capitales pueden ejercer «precios de monopolio». En tal caso los precios se fijan por debajo del valor de la mercancía y permiten una transferencia de valor hacia capitales de países que ejercen el poder de monopolio comprador.

c) Lo mismo ocurre si las mercancías son producidas únicamente por capitales transnacionales nacionales de los países donde la composición de valor es mayor; tampoco hay competencia, pero se generan precios de monopolios vendedores y las mercancías adquieren costos por encima de su valor al transferir plusvalor hacia los productores en forma de ganancia extraordinaria.

d) Los créditos internacionales constituyen otro mecanismo de transferencia de plusvalor por intereses fijados por los países dominantes; los efectos inmediatos son las célebres deudas externas que fungen como espada de Damocles en las economías dependientes.

e) La inversión extranjera de las corporaciones transnacionalizadas es otra forma de succión de plusvalor hacia los países de origen, ya que tales capitales pueden producir por debajo del valor de los capitales nacionales, pagar a la fuerza de trabajo por debajo del valor y embolsarse ganancias extraordinarias. ${ }^{21}$

El papel del Estado es un pendiente más en el proyecto de investigación de Marx (al igual que el mercado mundial). Engels y Lenin, seguidores de su obra, desarrollaron algunos aspectos. No obstante, parece necesario avanzar

${ }^{21}$ Enrique Dussel, op. cit. en categorías que vinculen la función que tienen los Estados nacionales en permitir/trabar la apropiación de valor o las transferencias que ocurren desde el capital nacional transnacionalizado de países periféricos y los capitales transnacionalizados más desarrollados.

Otros tópicos pendientes de resolución en cuanto al aspecto teórico, abstracto y en sus especificidades teóricas más concretas son las formas actuales de los imperialismos, las guerras económicas o políticas y su relación con la acumulación de capital; ello con la intención de examinar el devenir histórico de las etapas más actuales del capitalismo mundial y sus efectos en las formaciones sociales nacionales.

Enzo Faletto, en sintonía con los planteamientos de Paul Singer para la región latinoamericana, identifica tres periodos de dependencia: «dependencia consentida», que abarca desde el siglo XIX hasta 1914; «dependencia tolerada», de 1918 a 1980; $\mathrm{y}$ «dependencia deseada», después de 1980. ${ }^{22}$ En la última fase, los Estados nacionales, bajo la presión explícita de sus capitales transnacionalizados, se subsumen a la institucionalidad de la burguesía transnacional para incluso articular sus sistemas jurídicos y su organización política con el modelo anglosajón u otras formas nuevas que permitan los flujos de plusvalor hacia el núcleo de la acumulación mundial.

Es innegable la pertinencia de las ideas marxistas en estos temas, las formas actuales de la dominación capitalista no son el destino inevitable de América Latina, sino el desafío inminente para emprender un trabajo teórico serio y una organización política imprescindible hacia una liberación que no admite ya la menor demora.

\footnotetext{
${ }^{22}$ Beatriz Stolowicz, El misterio del posneoliberalismo, Colombia, Espacio Crítico Ediciones, 2016.
} 


\section{Consideraciones finales: la ciencia como práctica social}

Nadie combate la libertad;

a lo sumo combate la libertad de los demás.

La libertad ha existido siempre,

pero unas veces como privilegio de algunos, otras veces como derecho de todos.

Karl Marx

La ciencia en tanto práctica social no está exenta de los designios de la clase dominante, y, en particular, las universidades públicas, en tanto aparatos ideológicos del Estado, tampoco se apartan demasiado de la práctica político-ideológica indispensable para sostener la dominación. Por supuesto, los controles que la «práctica política» dominante impone al desarrollo de la ciencia son conocidos y no constituyen un monopolio de los países capitalistas, menos aún, de la teoría económica.

En varios países de América Latina las universidades $-\mathrm{y}$ también los centros privados de investigación - mantienen líneas de trabajo muy estrictas, de manera que los docentes o investigadores que no se ajustan a las «modas» dominantes no tienen cabida en ellas. En México, quizá la realidad sea diferente, pero en otros casos los intelectuales «críticos» se encuentran reducidos a determinados lugares del ámbito académico, aislados de otros, por lo que el debate nunca sucede. Ninguna de esas prácticas contradice la organización político-ideológica de la clase hegemónica, si bien la primera crea un impacto - o reacción - negativo en lo académico, la segunda propicia una práctica teórica «acomodada a las instituciones» que representa, desconectada de cualquier otra. En numerosos casos «los marxistas» aparecen como meros propagadores de algo distinto, curioso y muerto, tan lejano del mundo de los vivos que «se pudre en una escolástica pseudo dialéctica de corte profundamente burocrático y conservador» ${ }^{23}$ Es esta la historia de una teoría revolucionaria que, enmarcada en una práctica conservadora, se convierte en un simple testigo del pensamiento económico.

Las tareas para los marxistas, propuestas por Héctor Guillén ${ }^{24}$ para avanzar en el desarrollo de un método de análisis y transformación con importantes ventajas son tres: a) conocer a detalle los planteamientos críticos; b) avanzar en la crítica interna de la economía burguesa; c) tratar de discernir entre los «economistas vulgares» y los «economistas burgueses», entre un Friedman y un Minsky, entre un Roemer y un Keynes.

Si se mejora en el sentido indicado, con seguridad se podrían definir las formas de comparación que merecen los diferentes esquemas teóricos de la economía. Probablemente resulte inútil — por lo menos para el marxismoaminorarlo y refuncionalizarlo de tal manera que sólo se digne a responder las preguntas apologéticas que los economistas burgueses le obligan a realizar.

En opinión de Göran Therborn, ${ }^{25}$ «con el regreso del socialismo desde la ciencia a la utopía» la teoría social crítica deberá tomar nuevamente un lugar preponderante. Los problemas que estuvieron en la base del nacimiento de la teoría de Marx, los cuales intentó esclarecer al apuntar los caminos de la transformación necesaria, siguen vigentes. Aunque el «concreto pensado» de Marx ha cambiado de modo considerable, los nuevos problemas de la actual «globalización» conllevan «interdependencia global»y «miseria global», de ahí que un «entendimiento dialéctico de la unidad

\footnotetext{
${ }^{23}$ José Valenzuela Feijóo, Cuadernos de trabajo de economía política, serie Teoría del valor, núm. 2, México, Facultad de Economía-Universidad Nacional Autónoma de México, 1989. p. 24.

${ }^{24}$ Héctor Guillén Romo, «Algunos problemas de interpretación en la teoría de precios de producción de Piero Sraffa», Problemas del Desarrollo, vol. 10, núm. 39, 1988.

${ }^{25}$ Göran Therborn, «Dialectics of modernity: on critical theory and legacy of twentieth-century marxism», New Left Review, núm. 215, enero-febrero, 1996.
} 
de contrarios es el llamado de hoy, no menos acuciante que en tiempos de Karl Marx». Como rescata Therborn, ${ }^{26}$ «el más obvio» de los futuros para la «teorización» inspirada por Marx se halla en dilucidar el estado actual de la confrontación básica de las fuerzas sociales en el capitalismo y «las relaciones de producción a escala global y sus efectos sobre las relaciones sociales (...) El marxismo puede no tener soluciones prontas, pero su año crítico no necesariamente ha pasado». He aquí nuestro desafío.

${ }^{26}$ Idem.

Las formas actuales de la dominación capitalista no son el destino inevitable de América Latina, sino el desafío inminente para emprender una organización política imprescindible hacia una liberación que no admite ya la menor demora.

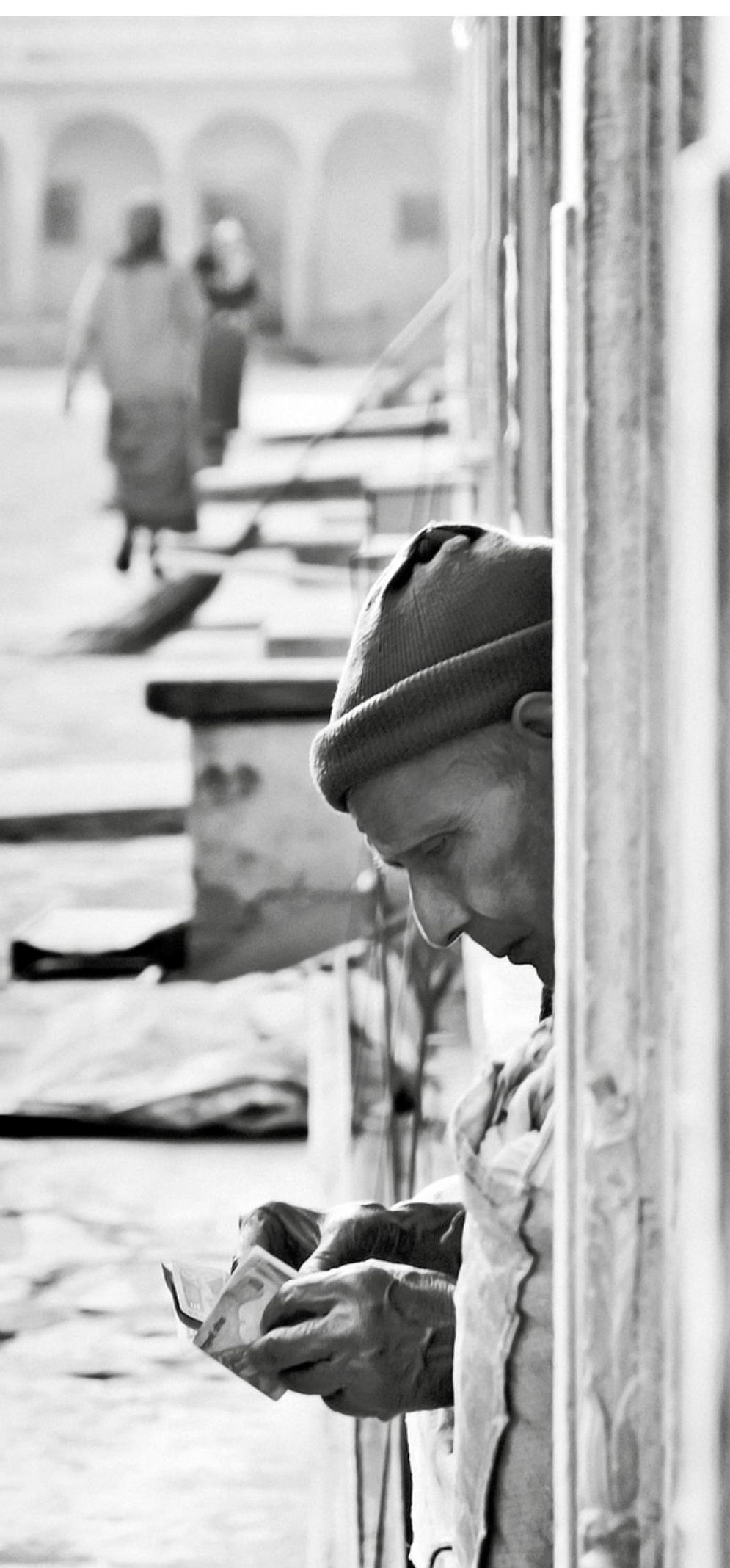

